\title{
1-Aminocyclopropane-1-Carboxylate: A Novel and Strong Chemoattractant for the Plant Beneficial Rhizobacterium Pseudomonas putida UW4
}

\author{
Tao Li, Jun Zhang, Chaohui Shen, Huiru Li, and Liyou Qiu ${ }^{\dagger}$ \\ College of Life Sciences, Henan Agricultural University, Key Laboratory of Enzyme Engineering of Agricultural Microbiology, \\ Ministry of Agriculture, Zhengzhou, 450002, China \\ Accepted 6 January 2019.
}

\begin{abstract}
Plant growth-promoting rhizobacteria (PGPR) and fungibacterial biofilms are both important biofertilizer inoculants for sustainable agriculture. However, the strongest chemoattractant for bacteria to colonize the rhizosphere and mycelia is not clear. Coincidentally, almost all the PGPRs possess 1aminocyclopropane-1-carboxylate (ACC) deaminase (AcdS) and can utilize $\mathrm{ACC}$ as the sole nitrogen source. Here, we found that ACC was a novel, metabolic dependent and methylaccepting chemoreceptor-involved chemoattractant for Pseudomonas putida UW4. The chemotactic response of UW4 to ACC is significantly greater than that to the amino acids and organic acids identified in the plant root and fungal hyphal exudates. The colonization counts of the UW4 acdS or cheR deletion mutants in the wheat rhizosphere and on Agaricus bisporus mycelia were reduced one magnitude compared with those of UW4. The colonization counts of UW4 on A. bisporus antisense ACC oxidase mycelia with a high ACC production significantly increased compared with $A$. bisporus, followed by the UW4 cheR complementary strain and the ethylene chemoreceptor gene-deletion mutant. The colonization counts of the UW4 strains on $A$. bisporus acd $S^{+}$mycelia with a low ACC production decreased significantly compared with $A$. bisporus wild type. These results suggested that ACC and not ethylene should be the strongest chemoattractant for the PGPR that contain AcdS.
\end{abstract}

Plant growth-promoting rhizobacteria (PGPR) are a heterogeneous group of bacteria that inhabit the rhizosphere and benefit plants (Kloepper and Schroth 1978; Saharan and Nehra 2011). The mechanisms include the improvement of nutrient availability, the modification of plant growth-regulator levels, biocontrol, the induction of systemic resistance, and bioremediation (Solano et al. 2008). Thus, the application of PGPR as biofertilizers has been dramatically increasing worldwide to minimize the use of chemicals and synthetic

${ }^{\dagger}$ Corresponding author: L. Qiu; qliyou@henau.edu.cn

Funding: We are grateful to Henan Provincial Science and Technology Department for financial support (project 162102110009).

*The $\boldsymbol{e}$-Xtra logo stands for "electronic extra" and indicates that two supplementary figures are published online.

The author(s) declare no conflict of interest.

๑) 2019 The American Phytopathological Society fertilizers and pesticides and to improve agricultural sustainability (Glick 2012; Vejan et al. 2016). However, the positive effects of the PGPR to the plants are less consistent in the field compared with those in the laboratory and greenhouse experiments (Ahmad et al. 2011; Vejan et al. 2016). The reason has remained unclear.

Fungal-bacterial biofilm (FBB) formed by PGPR and common soil fungi or fungi grown for mushrooms has essentially been considered to be a novel inoculant biofertilizer (Seneviratne et al. 2010; Velmourougane et al. 2017). FBB can enhance PGPR metabolic activities and rhizobial survival compared with solitary PGPR, leading to improved biofertilization and biocontrol effects (Jayasinghearachchi and Seneviratae 2010; Seneviratne and Jayasinghearachchi 2003; Seneviratne et al. 2008). PGPR are capable of chemotaxis, not only toward the rhizosphere and forming biofilms but also toward the fungal hyphosphere in which they form physical associations (bacterial-fungal complexes), such as planktonic, biofilm, and intrahyphal colonization (Frey-Klett et al. 2011). However, there has not been any direct evidence to prove that the methyl-accepting chemoreceptor (MCP) is involved in the chemotaxis of bacteria to fungi (Velmourougane et al. 2017).

To be effective, PGPR strains critically depend on their ability to colonize and survive in the rhizosphere when released into the environment (Chin-A-Woeng et al. 2000; PizarroTobías et al. 2015; Suslow and Schroth 1981). The first step for rhizosphere colonization by PGPR is to recognize the plantroot exudates (Espinosa-Urgel et al. 2002); they are attracted by the exudates as the chemoattractant, move to the rhizosphere, reproduce, and form biofilms in the rhizosphere (Lugtenberg et al. 2001). Bacterial chemotactic motility is mediated by a central two-component system, in which the essential signaling components are the MCP, histidine kinase CheA, methylesterase $\mathrm{CheB}$, methyltransferase $\mathrm{CheR}$, and the response regulator CheY (He and Bauer 2014). In addition to a chemoattractant gradient, once one or more of the essential signaling components is absent, the bacterial chemotaxis does not occur (Zhulin 2016).

Root and hyphal exudates are often divided into two classes of compounds, low- and high-molecular weight compounds. Low-molecular weight compounds include amino acids, organic acids, sugars, phenolics, and other secondary metabolites, while high-molecular weight compounds include polysaccharides and proteins with a less diverse but larger proportion of the root exudates by mass (Bais et al. 2006; Grewal and Rainey 1991). It is being investigated which compound in root exudates is the key component for PGPR chemotaxis and rhizosphere colonization. 
Compared with amino acids and organic acids, sugars often do not result in a strong chemotactic response from the PGPR. Pseudomonas fluorescens WCS365 did not respond to sugars from tomato root exudates but did respond to some organic acids and amino acids. Malic acid and citric acid are stronger chemoattractants than the other organic acids in tomato root exudates (de Weert et al. 2002). Similarly, P. fluorescens Pf0-1 showed the strongest response to L-malate, serine, and cysteine among the compounds from the tomato root exudates (Oku et al. 2012, 2014). Several dicarboxylic acids and amino acids glutamate and aspartate in soybean seed and root exudates were strong attractants for Bradyrhizobium japonicum (Barbour et al. 1991). Azospirillum strains showed maximal attraction to some organic acids from the root exudates of wheat, maize, and Leptochloafusca spp. (Reinhold et al. 1985). Three amino acids, arginine, glycine, and lysine, gave significant positive responses to Rhizobium leguminosarum (Gaworzewska and Carlile 1982). However, those amino acids and organic acids in the root exudates were also chemoattractants for deleterious rhizobacteria (DRB) (Begonia and Kremer 1994) or nonrhizobacteria (Yang et al. 2015). Therefore, PGPR must compete for the chemoattractants from the root exudates with other DRB and nonrhizobacteria in soil.

1-Aminocyclopropane-1-carboxylate (ACC) is a nonprotein amino acid and the immediate precursor of ethylene. It is synthesized by ACC synthase in the roots and transported to plant shoots, in which it is converted to ethylene by ACC oxidase (ACO) (Bradford and Yang 1980; Else and Jackson 1988). Abiotic and biotic stresses and the phytohormone indole-3-acetic acid (IAA) induce the transcription of the plant enzymes ACC synthase and ACO and stimulate the synthesis of ACC and ethylene (Hyodo et al. 1993; Kato et al. 2000; Kende and Zeevaart 1997). Additionally, ACC is a common exudate from seeds and roots, especially under environmental stress (Grichko and Glick 2001; Penrose and Glick 2001). It has not been reported whether ACC is a bacterial chemoattractant.

Almost all the PGPRs possess ACC deaminase (AcdS). The production of the enzyme and the utilization of ACC as the sole nitrogen source are one of the key traits for PGPR (Etesami et al. 2015; Glick 2014; Gontia-Mishra et al. 2014, 2017; Ma et al. 2003; Nascimento et al. 2014). AcdS can cleave ACC into ammonium and $\alpha$-ketobutyrate and decrease the ACC level in plant tissues; as a result, plant ethylene levels are reduced and the plants are protected from the inhibitory effects of stress ethylene (Glick 2014; Glick et al. 1994, 2007). In addition, PGPR mutants negative for AcdS not only do not stimulate root elongation (Glick et al. 1994; Li et al. 2000; Sun et al. 2009), but they also have significantly reduced rhizosphere colonization ability (Gamalero et al. 2008), while PGPR transformants harboring an exogenous $a c d S$ gene show a high plant growth-promoting activity with a low inoculum concentration (Holguin and Glick 2001) or with a high nodulation ability (Nascimento et al. 2012a and b). Interestingly, more than 50\% of the culturable bacteria in the rhizosphere of wild barley grown under the high solar radiation, temperature, and seasonally drought-stressful south-facing slope of the Evolution Canyon, Israel, are AcdS-producing bacteria, while only fewer than $5 \%$ were identified on the unstressful north-facing slope (Timmusk et al. 2011), likely due to higher ACC levels in the rhizosphere of stressed plants on the south-facing slope that can attract and support higher bacterial numbers containing AcdS, as compared with the north-facing slope. Similarly, approximately $20 \%$ of the culturable bacteria in the casing soil of Agaricus bisporus are AcdS-producing bacteria (Chen et al. 2013). A. bisporus is the only fungus known that produces ethylene via ACC (Zhang et al. 2016). Thus, we propose that the ACC secreted by the roots and fungal mycelia should be a chemoattractant or a key chemoattractant for the AcdSproducing PGPR, and the interaction between the PGPR and ACC from the root may be the deciding factor in PGPR rhizosphere colonization and, subsequently, the extent of plant growth promotion.

In this study, we report an analysis of the PGPR strain Pseudomonas putida UW4, a typical PGPR strain (Heydarian et al. 2016), responses to the ACC attraction and how this specific trait influences the rhizosphere and fungal mycelial colonization by UW4. $P$. putida UW4 harbors the acdS gene and has AcdS enzyme activity (Li et al. 2000).

\section{RESULTS}

Chemotaxis to ACC by the strains of $P$. putida $\mathrm{UW4}$.

The chemotaxis of the $P$. putida UW4 strains toward ACC was tested in swimming plates. P. putida UW4 was chemotactic

UW4 UW4 UW4 $\triangle$ cheR UW4 $\Delta$ cheR + cheR
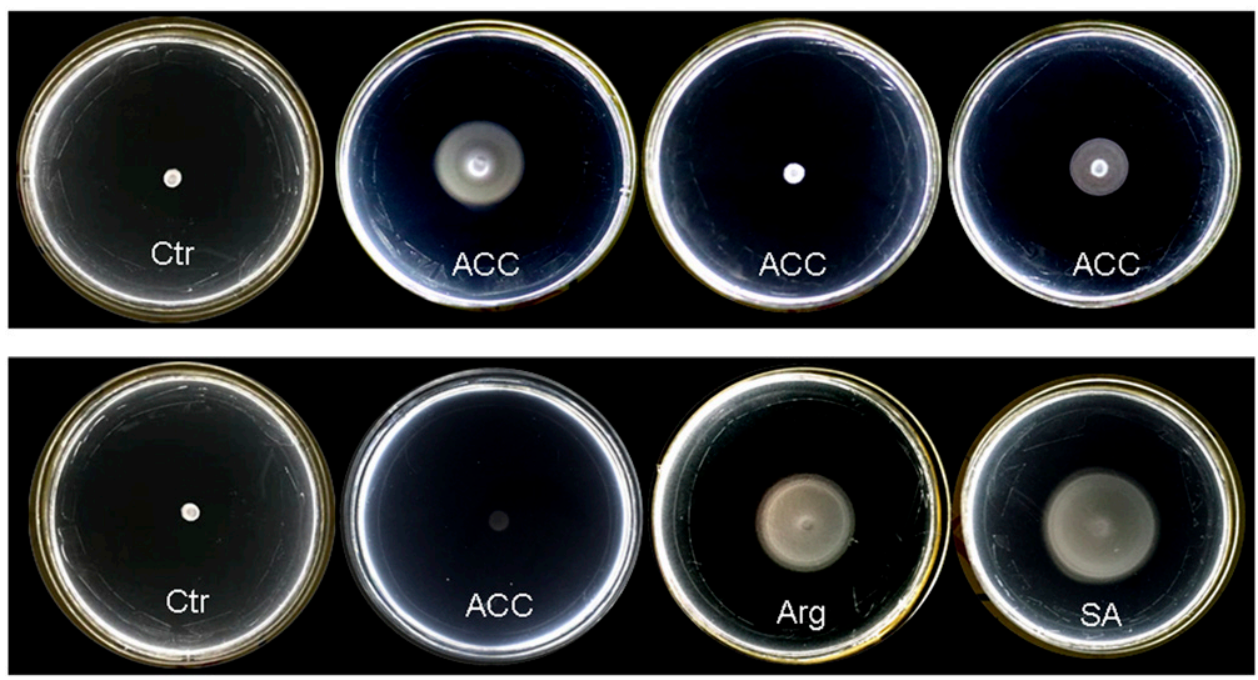

UW4 $\triangle$ acdS

UW4 $\triangle$ acdS

UW4 $\triangle$ acdS

UW4 $\triangle$ acdS

Fig. 1. Chemotaxis of Pseudomonas putida UW4 and its mutants toward 1-aminocyclopropane-1-carboxylate (ACC), arginine (Arg), and succinic acid (SA) on swimming plates. 
toward ACC except for $P$. putida UW4 $\Delta a c d S$, which was still capable of chemotaxis toward arginine and succinic acid. Following the deletion of cheR, UW4 also lacked chemotaxis toward ACC, while the trait was recovered in its complemented strain UW4 $\Delta c h e R+c h e R$ (Fig. 1). The cheR mutant showed no chemotaxis to ACC, indicating that the MCP was involved in the chemotaxis of UW4 to ACC. UW4 utilizes ACC as a sole nitrogen source, but this is not the case for UW4 $\triangle a c d S$ (Li et al. 2000), demonstrating AcdS activity in bacteria is associated with their ability to use ACC as a sole nitrogen source (Penrose and Glick 2003) and ACC was a metabolic-dependent chemoattractant for UW4. The growth rates on Luria Bertani (LB) medium of the UW4 strains were not significantly different (Supplementary Fig. S1).

\section{Comparison of the chemotactic strength} of $P$. putida UW4 to ACC and the other compounds in root and hyphal exudates.

The chemotactic strength of $P$. putida UW4 to ACC and the other compounds in root and hyphal exudates was semiquantitatively evaluated using a swimming plate chemotaxis
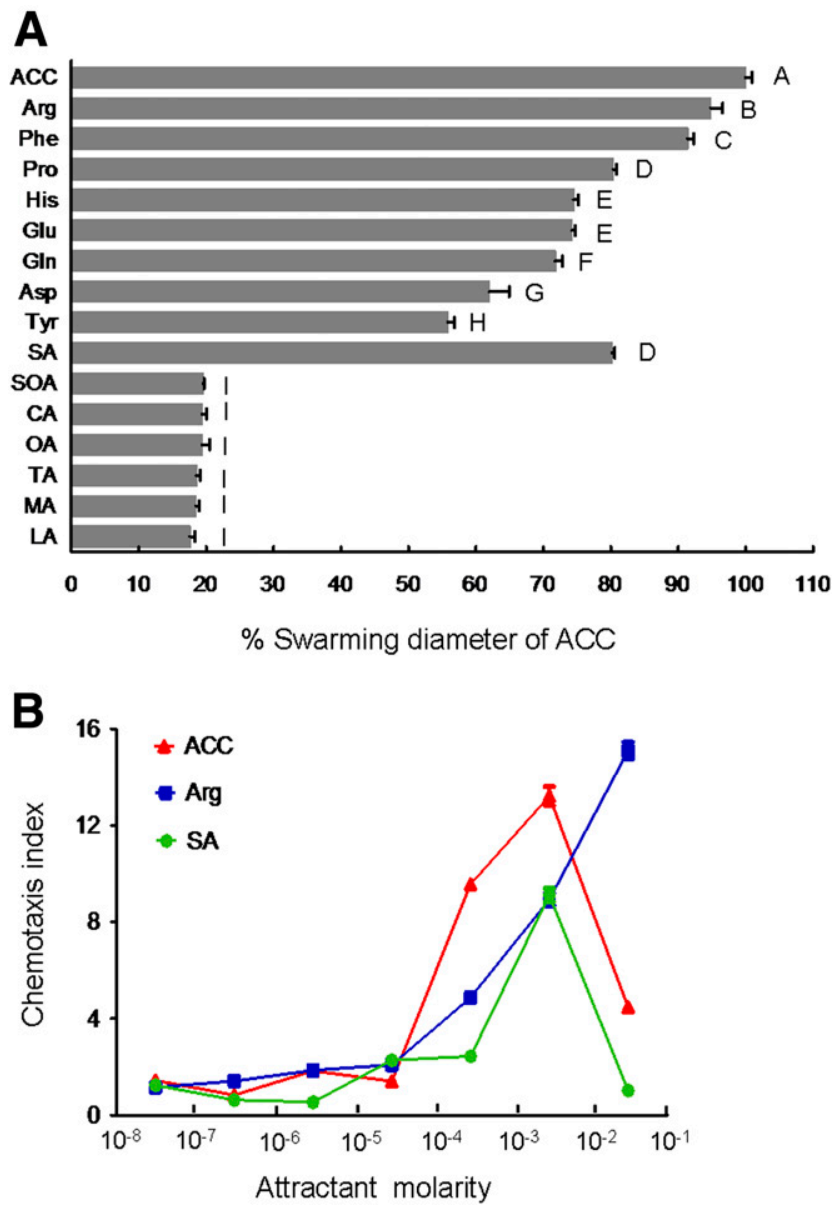

Fig. 2. The chemotactic response of Pseudomonas putida UW4 to the selected amino acids and organic acids. A, The swimming diameters of UW4 chemotaxis toward the selected amino acids and organic acids expressed as the percentage relative to that of 1-aminocyclopropane-1carboxylate (ACC). B, Concentration-response curves for UW4 chemotaxis toward ACC, arginine (Arg), and succinic acid (SA), using quantitative capillary chemotaxis assay. Asp $=$ aspartic acid, $\mathrm{CA}=$ citric acid, Gln = glutamine, Glu = glutamic acid, His = histidine, $\mathrm{LA}=$ lactic acid , $\mathrm{MA}=$ malic acid, $\mathrm{OA}=$ oxalic acid, Phe $=$ phenylalanine, Pro $=$ proline SOA $=$ sorbic acid, $\mathrm{TA}=$ tartaric acid , and Tyr $=$ tyrosine. Data are presented as mean \pm standard deviation. Data designated with the same upper case letters are not significantly different $(P<0.01)$. assay. In the assay, the average swimming diameters were expressed as the percentage relative to that of ACC as a chemoattractant (defined as 100\%), modified from an assay described previously (Greer-Phillips et al. 2004; Wallace and Frazier 1979). The chemotactic strength of ACC was significantly higher than that of the other compounds, including eight representative amino acids and seven representative organic acids from root and hyphal exudates. Arginine and succinic acid had a higher chemotactic strength than those of the other amino acids and organic acids (Fig. 2A).

A quantitative evaluation of the chemotactic strength of $P$. putida UW4 to ACC and the other compounds in the root and hyphal exudates was performed using a quantitative capillary chemotaxis assay. Arginine and succinic acid were selected to be the representative amino acid and organic acid from the root and hyphal exudates, respectively. The concentration-response curves for ACC, arginine, and succinic acid were integrated in Figure $2 \mathrm{~B}$. ACC and arginine had a similar chemotactic activity for $P$. putida UW4, with an approximate threshold of $5 \times 10^{-5}$ $\mathrm{M}$, while succinic acid was a relatively weaker attractant, with a threshold of $3 \times 10^{-4} \mathrm{M}$. The peak concentrations of the three attractants, ACC, arginine, and succinic acid, were $5 \times 10^{-3}$, $5 \times 10^{-2}$, and $5 \times 10^{-3} \mathrm{M}$, respectively (Fig. 2B). The results revealed that the chemotactic strength of UW4 to ACC was much higher than that of both arginine and succinic acid.

\section{Identification of the ethylene chemoreceptor gene in $P$. putida UW4.}

ACC is the direct precursor for ethylene in higher plants and A. bisporus (Chen et al. 2013; Zhang et al. 2016). Ethylene is a chemoattractant for Pseudomonas strains. Thus, ethylene chemotaxis is proposed to play an important role in plant-microbe interactions (Kim et al. 2007). In this study, we constructed a homolog of the $P$. aeruginosa ethylene chemoreceptor gene $(\operatorname{tlp} Q)$ deletion mutant of $P$. putida UW4 to investigate the effect of ethylene chemotaxis on its colonization of the rhizosphere. The homologous ethylene chemoreceptor gene-deletion mutant UW4 $\triangle m c p E$ demonstrated a markedly decreased chemotactic response to ethylene, while its complementary strain, UW4 $\Delta m c p E+m c p E$, harboring plasmid pSC27 (carrying $m c p E$ ), restored the ability of UW4 $\triangle m c p E$ to chemotactically respond to ethylene (Fig. 3). The growth rates on LB medium of the three UW4 strains were not significantly different. The results indicated that the $m c p E$ gene was the ethylene chemoreceptor gene in UW4.

\section{Colonization in the wheat rhizosphere by $P$. putida UW4 strains.}

The colonization counts of $P$. putida UW4 strains in the wheat rhizosphere were determined using quantitative polymerase chain reaction (qPCR). The count of UW4 was a magnitude higher than that of UW4 $\Delta a c d S$, as described in a previous study (Gamalero et al. 2008). Similarly, the count of UW4 was a magnitude higher than that of UW4 $\Delta$ cheR but did not differ from the UW4 $\Delta c h e R$ complementary strain UW4 $\Delta c h e R+c h e R$. There was no difference between the colonization counts of UW4 $\triangle m c p E$ and its complementary strain UW4 $\Delta m c p E+m c p E$ (Fig. 4).

Wheat seedlings were inoculated by substituting UW4-GFP and UW4 $\Delta a c d S$-GFP for UW4 and UW4 $\Delta a c d S$. The fluorescence intensity of the wheat roots inoculated with UW4-GFP was much higher than that inoculated with UW4 $\Delta a c d S$-GFP (Fig. 5).

\section{Colonization on $A$. bisporus mycelia by $P$. putida UW4 strains.}

To investigate the effect of ethylene on the primordial formation, we constructed two transformants of the button mushroom A. bisporus as $A C O$ and $A$. bisporus acd $S^{+}$. A. 
bisporus as $A C O$ was an antisense $A C O$ transformant of A. bisporus with downregulation expression of the $A C O$ gene by RNA interference. The ACC content increased and ethylene production was reduced in the mycelia of $A$. bisporus as ACO. A. bisporus acd $S^{+}$was constructed by introducing the UW4 acdS gene to A. bisporus, therefore, the transformant had AcdS activities and can cleave ACC produced by its own mycelia and both the ACC content and ethylene production in the mycelia were reduced (Zhang et al. 2016). The colonization counts of the $P$. putida UW4 strains on the mycelia of A. bisporus acdS $S^{+}$were significantly lower than those of the $A$. bisporus wild type and $A$. bisporus as $A C O$. The colonization counts of $P$. putida UW4 strains on the mycelia of $A$. bisporus as $A C O$ were significantly higher than those of $A$. bisporus wild type, except for UW4 $\Delta a c d S$ and UW4 $\Delta c h e R$. The colonization counts of $P$. putida UW4 $\Delta c h e R+c h e R$ on the mycelia of the three mushroom strains, wild type, $A$. bisporus as $A C O$, and acd $S$ were all significantly higher than those of UW4 $\Delta c h e R$. The colonization counts did not differ between UW4 $\Delta m c p E$ and its complementary strain UW4 $\Delta m c p E+m c p E$ when they colonized the mycelia of the three mushroom strains (Fig. 6).

$P$. putida UW4 strains colonizing the A. bisporus mycelia were observed using a scanning electron microscope (SEM). Like the results obtained using qPCR, the bacterial colonies of UW4 and UW4 $\Delta c h e R+c h e R$ were markedly higher than those of UW4 $\Delta a c d S$ and UW4 $\Delta c h e R$ (Supplementary Fig. S2).

\section{DISCUSSION}

PGPR has AcdS, which can utilize ACC, a prolific compound in seed and root exudates. AcdS is an induced enzyme with a much lower level of ACC (Jacobson et al. 1994). In this study, we found that ACC was also a chemoattractant for PGPR such as $P$. putida UW4, which possess AcdS and can use ACC as the sole nitrogen resource. While the cheR deletion mutant of UW4 did not show chemotaxis to ACC, indicating that the MCP was involved in the chemotaxis of UW4 to ACC. In addition, the $a c d S$ deletion mutant of UW4 lacked chemotaxis to

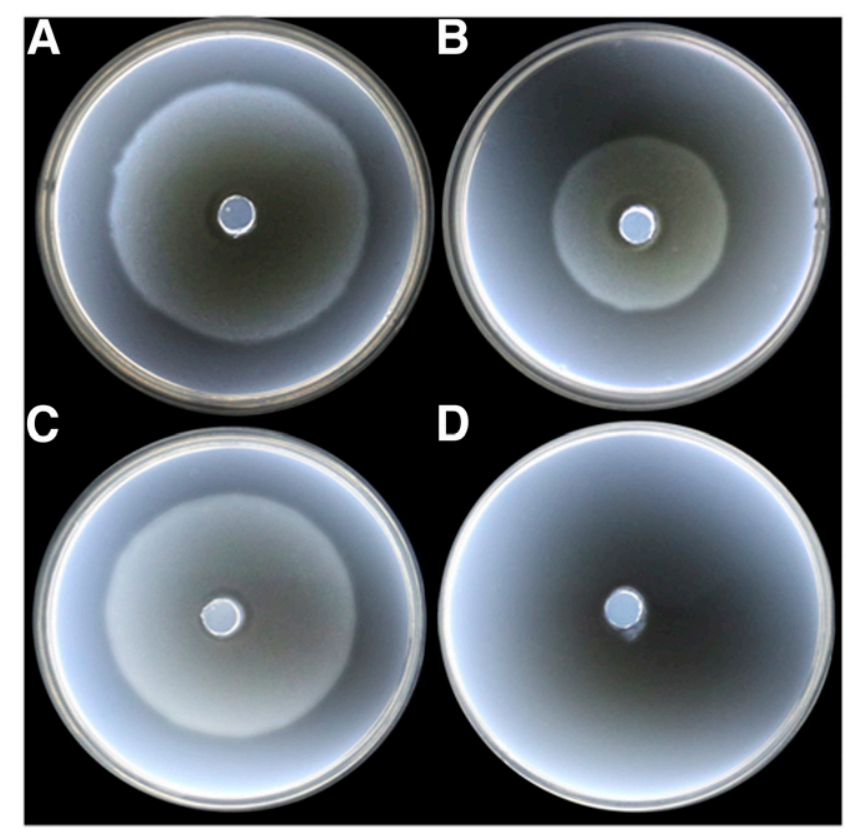

Fig. 3. Chemotactic response of Pseudomonas putida UW4 strains to ethylene in agarose plug assays. A, $P$. putida UW4. B, $P$. putida UW4 $\triangle m c p E$. C, $P$. putida UW4 $\triangle m c p E+m c p E$, which was a UW4 $\triangle m c p E$ complementary strain harboring plasmid pSC27 (carrying mcpE). D, P. putida UW4 response to the agarose plug not containing ethylene.
ACC and growth when ACC was the sole nitrogen source, indicating that ACC was a metabolic-dependent chemoattractant for PGPR.

Similar to a previous report (Chen et al. 2013), in this study, we found that $P$. putida UW4 enabled the colonization on A. bisporus mycelia and formed a biofilm. The colonization count of UW4 $\Delta c h e R$ on the mycelia was significantly decreased in comparison with UW4, but the colonization count was recovered in the UW4 $\Delta c h e R$ complementary strain UW4 $\Delta c h e R+c h e R$. The results indicated that chemotaxis with MCP is involved in the bacterial colonization on fungal mycelia and biofilm formation.

Several Pseudomonas strains can carry out chemotaxis to ethylene (Kim et al. 2007). However, there were no reports of ethylene as a root secretion. Under flooding conditions, soil microorganisms produce a large amount of ethylene at field capacity, which greatly increases the ethylene content in the soil (Smith and Russell 1969). The shoots still produce a large amount of ACC in the roots and then transport it to the upper part through the phloem and oxidize it to produce ethylene, promoting epinasty in flooded plants (Jackson 1997). There are not only numerous microorganisms that synthesize ethylene in the soil but, also, a large number of microorganisms that can utilize ethylene (Shennan 2006). Therefore, ethylene should not be a chemoattractant for PGPR to colonize the rhizosphere and fungal mycelia. In this study, the colonization counts of $P$. putida UW4 $\triangle m c p E$ and its complementary strain UW4 $\triangle m c p E+m c p E$ in the wheat rhizosphere were not different from each other. When colonizing the mycelia of $A$. bisporus as $A C O$ and $A$. bisporus $a c d S^{+}$, in which ethylene production decreased, the colonization counts of $P$. putida UW4 $\triangle m c p E$ and UW4 $\triangle m c p E+m c p E$ were also not different from each other. The results revealed that ethylene was not the chemoattractant for the PGPR to colonize the rhizosphere and fungal mycelia.

Although certain rhizobacterial strains show a chemotactic response to sugars with very low threshold concentrations (Loake et al. 1988), the mutants with a reduced ability to utilize sugars are not affected in their colonization ability in the rhizosphere (Lugtenberg et al. 1999), and many rhizobacterial strains do not respond to sugars (de Weert et al. 2002; Futamata et al. 1998). The mechanism of this is most likely due to the

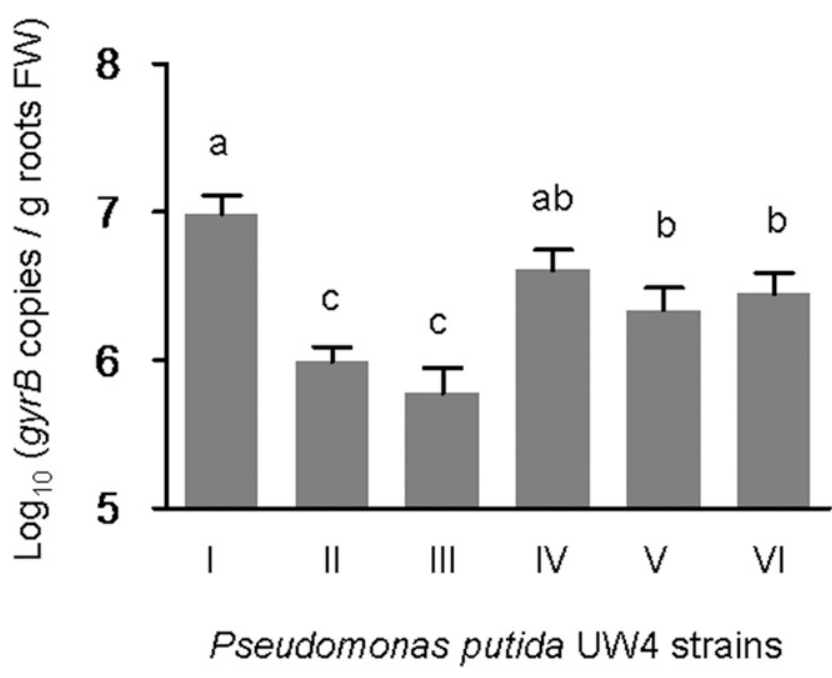

Fig. 4. The colonization counts of Pseudomonas putida UW4 strains in wheat rhizosphere. Column I shows colonization of $P$. putida UW4; II, UW4 $\Delta a c d S$; III, UW4 $\Delta c h e R$; IV, UW4 $\Delta c h e R+c h e R$; V, UW4 $\Delta m c p E$; and VI, UW4 $\triangle m c p E+m c p E$. Data are presented as mean \pm standard deviation. Data designated with the same lower case letters are not significantly different $(P<0.05)$. 
selective catabolism of amino acids over sugars that could enhance bacterial survival under nutrient-limiting conditions (Moe 2013). Therefore, sugars should not be the key chemoattractant for PGPR colonization of the rhizosphere.

The most abundant organic acid in $\mathrm{C} 4$ plant root exudates is malate, while in $\mathrm{C} 3$ plant root exudates, it is oxalate (Reinhold et al. 1985). Correspondingly, malate or oxalate are the most potent chemoattractants among the organic acids for the PGPR strains originating from $\mathrm{C} 4$ plants or $\mathrm{C} 3$ plants, respectively (Reinhold et al. 1985; Tan et al. 2013; Zheng and Sinclair 1996). The population levels of several PGPR strains colonized in the rhizosphere significantly increase after adding malate to the rhizosphere (Ling et al. 2011; Yuan et al. 2015). However, there are some exceptions. The strongest organic acid attractant of certain PGPR strains is succinic acid (Barbour et al. 1991; Gaworzewska and Carlile 1982). In a comparison of the chemotaxis response of PGPR strains to amino acids and organic acids, $P$. fluorescensWCS365 demonstrates a significant response to L-aspartic acid, L-glutamic acid, L-isoleucine, and L-leucine at 4 to $9 \mathrm{mM}$, while the response to malic acid took place at $10 \mathrm{mM}$ (de Weert et al. 2002). The threshold taxis concentration of Bacillus megaterium B153-2-2 for serine is $10^{-7} \mathrm{M}$, while for the best organic acid attractant malate, it is $10^{-6} \mathrm{M}$, and the peak taxis concentration of serine and malate are both $10^{-3} \mathrm{M}$ (Zheng and Sinclair 1996). Similarly, many rhizobacterial strains do not respond to organic acids (Futamata et al. 1998). Serine, arginine, or alanine are the strongest amino acid chemoattractants for some rhizobacterial strains (Chet et al. 1973; Ordal and Gibson 1977; Zheng and Sinclair 1996). In addition, the chemotactic response by B. megaterium B1532-2 cells is significantly increased after the addition of malate to the mixture of alanine, asparagine, serine, and threonine but significantly lower than that to soybean seed exudates. The authors suggest that one or more components other than amino acids and malate in the soybean seed exudates should act as chemoattractants for the B153-2-2 cells (Zheng and Sinclair 1996).

Certain PGPR strains are attracted to not only protein amino acids but also to the nonprotein amino acid $\gamma$-aminobutyric acid (GABA), an ACC-related compound present in seed and root exudates (Rico Jiménez et al. 2013). ACC is a nonprotein amino acid that occurs in high amounts in seed and root exudates, and PGPR strains with AcdS enzyme activity prefer to primarily utilize ACC rather than both ACC-related compounds $\alpha$-aminobutyric acid and $\gamma$-aminobutyric acid (Penrose and Glick 2001; Penrose et al. 2001). In addition, to maintain the dynamic equilibrium of the ACC concentration that exists between root, rhizosphere, and bacterium, the plant roots must continue to efflux ACC (Glick et al. 1998). Therefore, PGPR

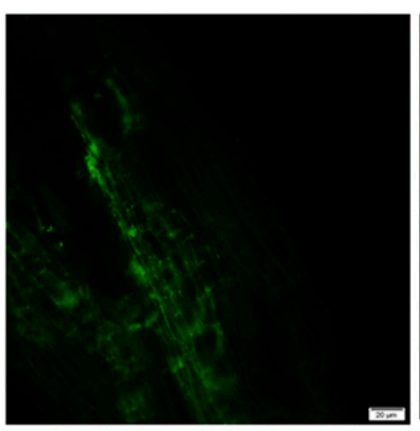

UW4-GFP

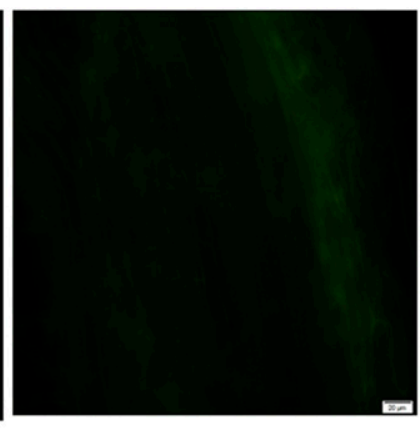

UW4 $\triangle$ acdS-GFP
Fig. 5. Fluorescence micrograph of the wheat roots colonized by Pseudomonas putida UW4-GFP and UW4 $\Delta a c d S$-GFP. The scale bar corresponds to $20 \mu \mathrm{m}$. strains possessing AcdS may be more competitive or persistent than other rhizosphere microorganisms in the soil (Glick 2014; Jacobson et al. 1994). After the deletion of the $\operatorname{acdS}$ gene, the rhizosphere colonization counts of $P$. putida UW4 decrease by one magnitude (Gamalero et al. 2008). Introducing or overproducing the acdS gene increases AcdS activities and the symbiotic efficiency of the rhizobia belonging to both the Alpha- and Betaproteobacteria classes (Conforte et al. 2010; Kong et al. 2015; Nascimento et al. 2012a and b, 2018; Tittabutr et al. 2008). Stress environments stimulate the synthesis and secretion of ACC in the plant roots and simultaneously increase the rhizosphere colonization of PGPR (Stromberger et al. 2017; Timmusk et al. 2011) and the nodulation of rhizobium (Nascimento et al. 2012b). Many fungi have ACC synthase and ACO genes in their genomes (Joint Genome Institute genomic data), so the mechanism of interaction of the PGPR strains that harbor the $a c d S$ gene to fungi should be similar to those with the plants mediated by ACC. In this study, we found that $P$. putida UW4 showed the strongest chemotactic response to ACC with a low threshold concentration compared with the other amino acids and organic acids that occurred in root or fungal mycelia exudates. These results suggest that ACC is likely to be the strongest chemoattractant for AcdS enzyme-producing PGPR.

The colonization counts of the $a c d S$ or cheR deletion mutants of $P$. putida UW4 in the wheat rhizosphere and on A. bisporus mycelia were reduced by one magnitude compared with the wild type. The ACC production of A. bisporus significantly impacted the colonization counts of UW4 strains on its mycelia. The colonization counts of UW4 on A. bisporus as ACO mycelia with high levels of ACC production significantly increased compared with $A$. bisporus, followed by UW4 $\Delta$ cheR+ cheR, $\triangle m c p E$, and $\triangle m c p E+m c p E$ but not UW4 $\triangle a c d S$ and $\Delta c h e R$. In contrast, the colonization counts of the UW4 strains on $A$. bisporus acd $S^{+}$mycelia with low ACC production significantly decreased compared with those of A. bisporus wild type. The results indicated that the chemotaxis toward ACC was involved in the greater colonization of UW4 on A. bisporus mycelia; ACC was likely to be the strongest chemoattractant for the AcdS enzyme produced by PGPR to chemotactically respond to the rhizosphere and fungal mycelia. The findings would contribute greatly to the efficient application of PGPR in the sustainable agriculture.

\section{MATERIALS AND METHODS}

\section{Microbes and plants.}

P. putida UW4 and UW4 $\Delta a c d S$ were provided by B. R. Glick, University of Waterloo (Ontario, Canada). P. putida UW4 was isolated from the rhizospheres of reeds, contained AcdS, and was grown on a medium with ACC as the sole source of nitrogen. UW4 $\Delta a c d S$ was an acdS-deficient mutant of UW4 created using homologous recombination (Li et al. 2000). Wheat (Triticum aestivum L.) variety Aikang 58 seeds were obtained from the National Engineering Research Centre for Wheat (Zhengzhou, China). A. bisporus (J.E. Lange) Imbach variety AS2796 was obtained from the Edible Fungi Institute of the Fujian Academy of Agricultural Sciences (Fuzhou, China) (Table 1).

\section{Construction of in-frame deletions.}

The $P$. putida UW4 genome (GenBank under accession number CP003880) possesses a chemotaxis protein methyltransferase (CheR) gene homolog cheR (GenBank accession number AFY21330.1) and the methyl-accepting chemotaxis protein for the ethylene gene homolog mcpE (GenBank accession number AFY18818.1). In-frame deletions of cheR and $m c p E$ in $P$. putida UW4 were constructed as described 
previously (Simon et al. 1983). The target gene flanking sequences (approximately $600 \mathrm{bp}$ upstream and downstream of the target gene) were PCR-amplified (primers are listed in Table 1) and were fused by fusion PCR. The fusion construct was cloned into the gene replacement plasmid pEX18Gm (Table 1). After conjugation of the plasmid into P. putida UW4, double recombinants were verified using PCR amplification across the site of the deletion.

\section{Complementation.}

The $c h e R$ and $m c p E$ genes were cloned, using PCR with primers designed to incorporate a HindIII or ClaI site at the $5^{\prime}$ end and a BamHI site at the $3^{\prime}$ end of the genes, and the resulting products were ligated into pBBR1MCS2 (Table 1). The plasmids were transformed into Escherichia coli $\mathrm{S} 17-1$ and were then transferred into $P$. putida UW4 in-frame deletion mutants via conjugation (Simon et al. 1983).

\section{Growth curve.}

$P$. putida UW4 strains were grown on LB medium and were shaken on a rotate shaker $(200 \mathrm{rpm})$ at $30^{\circ} \mathrm{C}$ for $10 \mathrm{~h}$. Growth curves were monitored by turbidimetric measurements at $600 \mathrm{~nm}$ and 0.5 - to 1 -h intervals.

\section{Swimming plate chemotaxis assay.}

The swimming plate chemotaxis assay was performed as described previously (Dekkers et al. 1998; Sarand et al. 2008) with slight modifications. Semisolid agar plates containing $0.3 \%$ agarose in chemotaxis buffer (Adler 1973) were used. The chemoattractants to be tested (except ethylene) were added to a final concentration of $0.3 \mathrm{mM}$. Bacterial cells from LB cultures (early log phase, optical density at $600 \mathrm{~nm}$ $\left.\left[\mathrm{OD}_{600}\right]=1.0\right)$ were pelleted, were washed twice with chemotoxis buffer, and were resuspended in chemotoxis buffer $\left(\mathrm{OD}_{600}\right.$ of approximately 2.0). A cell suspension of $2 \mu \mathrm{l}$ was gently poured in the center of the semisolid plate and was incubated at room temperature $\left(25^{\circ} \mathrm{C}\right)$. The formation of rings was observed after $72 \mathrm{~h}$ of incubation. Bacterial chemotaxis toward ethylene was tested using an agarose plug containing ethylene as the chemoattractant. The agarose plug containing ethylene was prepared as described previously (Kim et al. 2007).

\section{Quantitative capillary chemotaxis assay.}

Quantitative capillary chemotaxis assay was conducted using a method adapted from the traditional quantitative capillary assay (Adler 1973) and the high-throughput capillary assay (Liu et al. 2009). Bacterial cells were grown overnight $\left(\mathrm{OD}_{660}=\right.$ 0.3 to 0.45 ) in ACC-DF minimal media, in which the sole nitrogen source of $\left(\mathrm{NH}_{4}\right)_{2} \mathrm{SO}_{4}$ was replaced by ACC (Penrose and Glick 2003). The cells were harvested and washed twice with chemotoxis buffer precooled at $4{ }^{\circ} \mathrm{C}$ and were resuspended in chemotoxis buffer $\left(\mathrm{OD}_{600}\right.$ approximately 2.0). A 300- $\mu \mathrm{l}$ volume of the cell suspension was added into each well of the first 96-well plate, and $100 \mu \mathrm{l}$ of chemotaxis buffer or an attractant dissolved in chemotaxis buffer was added into each well of the second 96-well plate. One-microliter capillaries were sealed in a flame at one end and were sterilized, were quickly passed several times through the flame, and were immediately plunged, open end down, into the second plate well containing chemotaxis buffer or an attractant dissolved in chemotaxis buffer. After the buffer was drawn to one-third the volume of the capillary, the open end of the capillary was washed with chemotaxis buffer, and the sealed end was inserted into the wells of a third 96-well plate containing solidified $3 \%$ agar. The plate was then inverted, inserting the capillaries into the first plate wells. After incubation of this assembly at room temperature for $2 \mathrm{~h}$, the plate containing the capillaries was removed. The capillaries were picked out of the solidified agar, were washed with chemotaxis buffer, and the contents of each capillary were individually collected and diluted in a 2 -ml tube, and colonies were enumerated as colony-forming units by plate counts on LB plates.

The chemotactic strength of the chemotactic compounds was expressed as the chemotaxis index (CI), which was defined as the ratio of the number of colony-forming units produced from the capillary containing the test compound to that from a control capillary containing chemotaxis buffer without any chemotactic compound (Pandey et al. 2012). A CI of 2.0 or greater was considered to be significant (Moulton and Montie

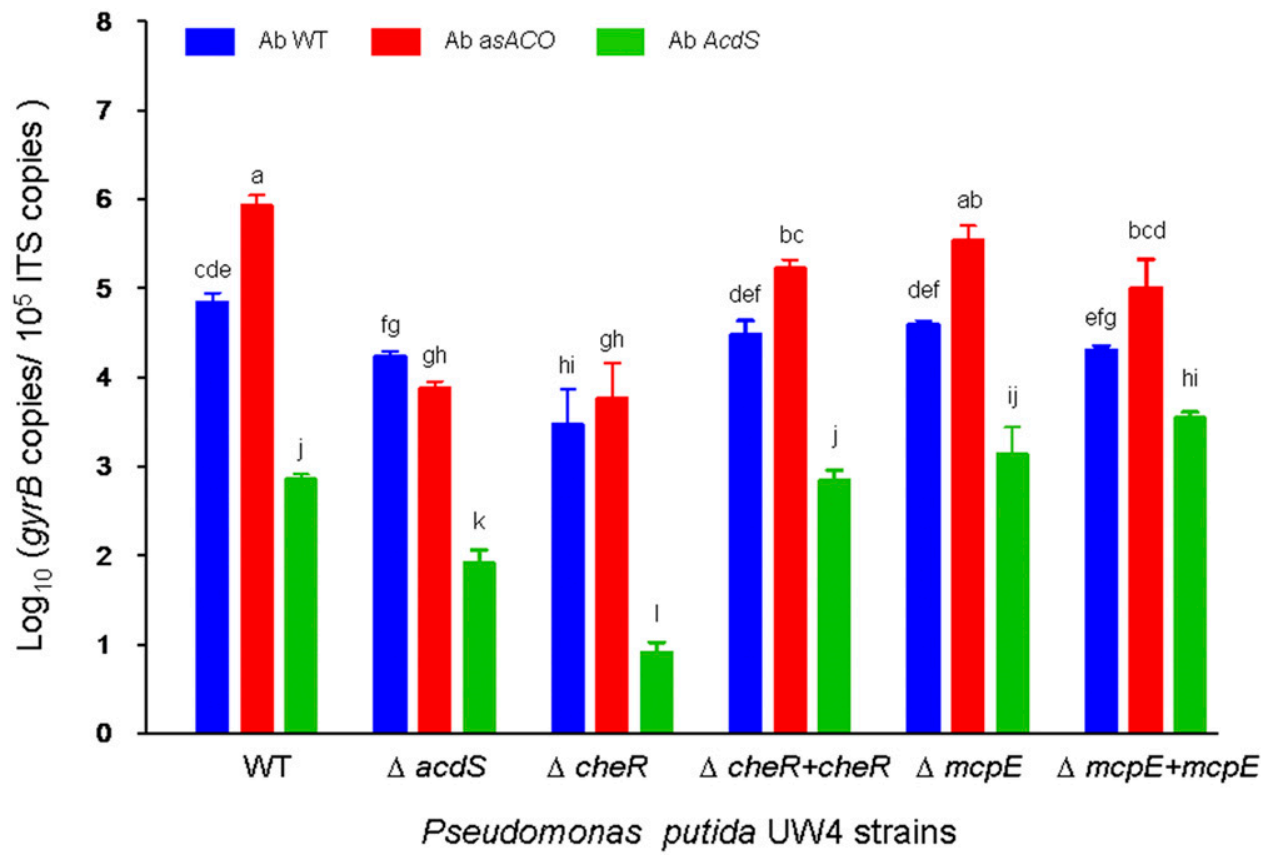

Fig. 6. The colonization counts of Pseudomonas putida UW4 strains on Agaricus bisporus mycelia. Ab WT =A. bisporus, Ab as ACO = A. bisporus as ACO, and $\mathrm{Ab}$ acdS $=$ A. bisporus acd $S^{+}$. 
1979). The terms response, threshold, peak, and background are used in this paper as defined by (Adler 1973).

\section{Wheat rhizosphere colonization by $P$. putida.}

Aikang 58 wheat seeds were surface-sterilized, and the sterile seedlings were cultivated on solidified Murashige and Skoog (MS) basal media and liquid MS basal media as previously described (Loyola-Vargas et al. 2007), with slight modifications. Eight-day-old seedlings were transferred to 300-ml plant tissueculture flasks (Meilun Biotech Co., Dalian, China), each containing $50 \mathrm{ml}$ of liquid MS basal media, and were incubated on a shaker at $40 \mathrm{rpm}$. Each three seedlings were fixed in a foam board and were placed in a flask. After $24 \mathrm{~h}$ of shock culturing, $1 \mathrm{ml}$ of P. putida bacterial suspension $\left(\mathrm{OD}_{600}=1.0\right)$ (the bacteria cells were cultured on LB media, then were harvested and suspended in liquid MS basal media) was added to each flask. The seedlings were continuously cultured for 7 days to determine the number of bacterial colonies in the wheat rhizosphere.

\section{A. bisporus mycelia colonization by $P$. putida .}

A. bisporus mycelia colonization by $P$. putida was performed as described previously (Jayasinghearachchi and Seneviratne 2004), with several modifications. A. bisporus AS2796 was cultured on potato dextrose agar (Haling Biotech Co., Shanghai, China) plates at $25^{\circ} \mathrm{C}$ for 14 days. A mycelia plug $15 \mathrm{~mm}$ in diameter from the peripheral edge of the AS2796 colony was inoculated centrally on a Petri dish. P. putida bacterial suspension $(200 \mu \mathrm{l}, \mathrm{OD}=1.0)$ (the bacteria cells were cultured on LB media, then were harvested and suspended in liquid MS basal media) was spread over the mycelia plug and was cocultured at $28^{\circ} \mathrm{C}$ for $30 \mathrm{~min}$.

\section{qPCR.}

The amount of bacteria colonized in the wheat rhizosphere and on A. bisporus mycelia was determined using qPCR. The wheat roots were gathered and were surface-dried using sterile filter paper. After weighing, the roots were ground in a tissue

Table 1. Strains, plasmids, and primers

\begin{tabular}{|c|c|c|}
\hline Strain, plasmid, primer or probe ${ }^{a}$ & Relevant characteristics or sequence $\left(5^{\prime}-3^{\prime}\right)^{\mathbf{b}}$ & Source or reference \\
\hline \multicolumn{3}{|l|}{ Pseudomonas putida } \\
\hline UW4 & Wild type; $a c d S$ & Shah et al. 1998 \\
\hline UW4 $\Delta a c d S$ & UW4 derivative; $a c d S:: \mathrm{Tc}^{\mathrm{R}}$ & Li et al. 2000 \\
\hline UW4 $\Delta c h e R$ & UW4 derivative; $\Delta c h e R$ & This study \\
\hline UW4 $\Delta c h e R+c h e R$ & UW4 $\Delta$ cheR complemented with $c h e R$ in pLT12 & This study \\
\hline UW4 $\Delta m c p E$ & UW4 derivative; $\triangle m c p E$ & This study \\
\hline UW4 $\triangle m c p E+m c p E$ & UW4 $\triangle m c p E$ complemented with $m c p E$ in $\mathrm{pSC} 27$ & This study \\
\hline UW4-GFP & UW4 derivative; transformed with plasmid pBBR1-GFP & This study \\
\hline UW4 $\Delta a c d S$-GFP & UW4 $\Delta a c d S$ derivative; transformed with plasmid pBBR1-GFP & This study \\
\hline \multicolumn{3}{|l|}{ Escherichia coli } \\
\hline DH5 $\alpha$ & 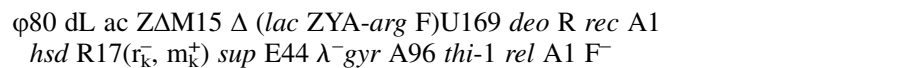 & Gibco BRL \\
\hline S17-1 & $\begin{array}{l}\left.\mathrm{Sm}^{\mathrm{R}}, \mathrm{EC} 294 \text { with integrated RP4-2 (Tc:: } \mathrm{Mu}\right)(\mathrm{Km}:: \mathrm{Tn} 7) \text { recA pro } \\
\text { hsdR RP4-2-Tc::Mu-Km::Tn7 } \lambda \text {-pir }\end{array}$ & Simon et al. 1983 \\
\hline Agaricus bisporus AS2796 & Wild type & Zhang et al. 2016 \\
\hline A. bisporus as $A C O$ & Antisense $A C O$ transformant of AS2796 & Zhang et al. 2016 \\
\hline A. bisporus acd $S^{+}$ & Transformant of AS2796 with the $a c d S$ gene of UW4 introduced & Zhang et al. 2016 \\
\hline \multicolumn{3}{|l|}{ Plasmid } \\
\hline pEX18Gm & Gene replacement vector, $\mathrm{Gm}^{\mathrm{R}}$ ori $\mathrm{T}^{+} \operatorname{sac} \mathrm{B}^{+}(5.8 \mathrm{~kb})$ & Hoang et al. 1998 \\
\hline pEX18Gm-cheR & $\begin{array}{l}\text { The } 600 \mathrm{bp} \text { upstream of UW } 4 \text { cheR fused to the } 600 \mathrm{bp} \text { downstream and cloned } \\
\text { into pEX18Gm to generate an in-frame deletion of cheR }\end{array}$ & This study \\
\hline pEX18Gm-mcpE & $\begin{array}{l}\text { The } 587 \mathrm{bp} \text { upstream of UW } 4 \mathrm{mcpE} \text { fused to the } 568 \mathrm{bp} \text { downstream and cloned } \\
\text { into pEX18Gm to generate an in-frame deletion of } m c p E\end{array}$ & This study \\
\hline pBBR1MCS2 & $\mathrm{Km}^{\mathrm{R}}$, lacPOZ' broad host vector with $\mathrm{R}$ type conjugative origin & Kovach et al. 1995 \\
\hline pBBR1MCS2- cheR & pBBR1MCS2 harboring cheR under the control of PlacZ & This study \\
\hline pBBR1MCS2-mсрE & pBBR1MCS2 harboring $m c p E$ under the control of PlacZ & This study \\
\hline pBBR1-GFP & pBBR1MCS harboring $g f p$ under the control of PlacZ & Ouahrani-Bettache et al. 1999 \\
\hline \multicolumn{3}{|l|}{ Primer and probe } \\
\hline cheR-UHA-F & CGGATCCGTTGTAGTTCGGGGTA, BamHI site incorporated & This study \\
\hline cheR-UHA-R & GAAAACAAGCAGGGTTACCTCTTCCTC & This study \\
\hline cheR-DHA-F & GAGGAAGAGGTAACCCTGCTTGTTTTC & This study \\
\hline cheR-DHA-R & GGAATTCCTGAAACCCAGCACAA, EcoRI site incorporated & This study \\
\hline cheR-complementary-F & CAAGCTTGGGGATTTGTGGTGT, HindIII site incorporated & This study \\
\hline cheR-complementary-R & CGGATCCGATATCAGCTAGGGG, BamHI site incorporated & This study \\
\hline mcpE-UHA-F & CGGAATTCCGTCCGATCATGTCGCCCAAGC, EcoRI site incorporated & This study \\
\hline mcpE-UHA-R & TCGAATAAGGACGCCTCCGCCTTGCAAAATCCCCAT & This study \\
\hline mcpE-DHA-F & ATGGGGATTTTGCAAGGCGGAGGCGTCCTTATTCGA & This study \\
\hline mcpE-DHA-R & $\begin{array}{l}\text { CGGGATCCTTGGCAATGGCCACGGCAAAAGCT, BamHI site } \\
\text { incorporated }\end{array}$ & This study \\
\hline mcpE-complementary-F & CCATCGATATGTCGCTCAGACAACTTTCCA, $C l a \mathrm{I}$ site incorporated & This study \\
\hline mcpE-complementary-R & CGGGATCCTTAAACGCGGAACTGGTCC, BamHI site incorporated & This study \\
\hline gyrB-qPCR-F & CCTGTCGGAAGAGCTGGT & This study \\
\hline gyrB-qPCR-R & ACCGTGGACGTAAGTCTGTT & This study \\
\hline gyrB-qPCR-probe & CTGACCGTTCGCCGTAGTGGCAAG & This study \\
\hline ITS-qPCR-F & GGATGTAAGGACTTGCAGTGTG & This study \\
\hline ITS-qPCR-R & GGCATAGCCCATGTAAAGACA & This study \\
\hline ITS-qPCR-probe & ACAGTGCTGTCCTTTACCTTGGCCA & This study \\
\hline
\end{tabular}

${ }^{\mathrm{a}} \mathrm{UHA}=$ upstream homologous arm, DHA = downstream homologous arm, CGMCC $=$ China General Microbiological Culture Collection Center, and ITS $=$ internally transcribed spacer.

${ }^{\mathrm{b}} \mathrm{Tc}^{\mathrm{R}}, \mathrm{Sm}^{\mathrm{R}}, \mathrm{Gm}^{\mathrm{R}}$, and $\mathrm{Km}^{\mathrm{R}}$ indicate, respectively, tetracycline, streptomycin, gentamycin, and kanamycin-resistant; $\mathrm{GFP}=$ green fluorescent protein; $A C O=$ 1-aminocyclopropane-1-carboxylate oxidase gene. 
grinder with $2 \mathrm{ml}$ of $1 \times$ phosphate buffered saline (PBS). The amount of $P$. putida was determined using gyrB (DNA gyrase B protein gene)-targeted qPCR (Watanabe et al. 1998). The $A$. bisporus mycelial plugs with the cocultured $P$. putida strains were washed using $10 \mathrm{ml}$ of PBS buffer on a shaker at $40 \mathrm{rpm}$ for $10 \mathrm{~min}$ and were then drained to remove the bacteria not colonized on the mycelia. The amounts of $A$. bisporus and $P$. putida were assessed using rDNA ITS (internally transcribed spacer)-targeted qPCR (Cretoiu et al. 2013) and gyrB-targeted qPCR.

\section{Fluorescence microscope observation.}

The wheat seedlings were inoculated with UW4-GFP and UW4 $\Delta a c d S$-GFP, respectively, and were shock-cultured for 7 days as above. The wheat roots were gathered and surfacedried with sterile filter paper. After that, the wheat roots were observed using a fluorescence microscope (Leica TCS SPE; Leica, Wetzlar, Germany).

\section{SEM observation.}

After draining to remove the bacteria not colonized on the mycelia, as described above, the A. bisporus mycelia were fixed, dehydrated, and coated for SEM observation as described previously (Masaphy et al. 1987) and were observed using SEM (Hitachi S-3400, Tokyo).

\section{Statistical analysis.}

All experiments were performed at least three times on duplicate or triplicate samples. Each assay was performed in triplicate. Comparisons among the means of three independent experiments used the least significant difference test.

\section{LITERATURE CITED}

Adler, J. 1973. A method for measuring chemotaxis and use of the method to determine optimum conditions for chemotaxis by Escherichia coli. J. Gen. Microbiol. 74:77-91.

Ahmad, F., Husain, F. M., and Ahmad, I. 2011. Rhizosphere and root colonization by bacterial inoculants and their monitoring methods: a critical area in PGPR research. Pages 363-391 in: Microbes and Microbial Technology. I. Ahmad, F. Ahmad, and J. Pichtel, eds. Springer-Verlag, New York.

Bais, H. P., Weir, T. L., Perry, L. G., Gilroy, S., and Vivanco, J. M. 2006. The role of root exudates in rhizosphere interactions with plants and other organisms. Annu. Rev. Plant Biol. 57:233-266.

Barbour, W. M., Hattermann, D. R., and Stacey, G. 1991. Chemotaxis of Bradyrhizobium japonicum to soybean exudates. Appl. Environ. Microbiol. 57:2635-2639.

Begonia, M. F. T., and Kremer, R. J. 1994. Chemotaxis of deleterious rhizobacteria to velvetleaf (Abutilon theophrasti Medik.) seeds and seedlings. FEMS Microbiol. Ecol. 15:227-235.

Bradford, K. J., and Yang, S. F. 1980. Xylem transport of 1aminocyclopropane-1-carboxylic acid, anethylene precursor, an ethylene precursor, in waterlogged tomato plants. Plant Physiol. 65:322-326.

Chen, S., Qiu, C., Huang, T., Zhou, W., Qi, Y., Gao, Y., Shen, J., and Qiu, L. 2013. Effect of 1-aminocyclopropane-1-carboxylic acid deaminase producing bacteria on the hyphal growth and primordium initiation of Agaricus bisporus. Fungal Ecol. 6:110-118.

Chet, I., Zilberstein, Y., and Henis, Y. 1973. Chemotaxis of Pseudomonas lachrymans to plant extracts and to water droplets collected from the leaf surfaces of resistant and susceptible plants. Physiol. Plant Pathol. 3: 473-479.

Chin-A-Woeng, T. F. C., Bloemberg, G. V., Mulders, I. H. M., Dekkers, L. C., and Lugtenberg, B. J. J. 2000. Root colonization by phenazine-1carboxamide-producing bacterium Pseudomonas chlororaphis PCL1391 is essential for biocontrol of tomato foot and root rot. Mol. PlantMicrobe Interact. 13:1340-1345.

Conforte, V. P., Echeverria, M., Sánchez, C., Ugalde, R. A., Menéndez, A. B., and Lepek, V. C. 2010. Engineered ACC deaminase-expressing free-living cells of Mesorhizobium loti show increased nodulation efficiency and competitiveness on Lotus spp. J. Gen. Appl. Microbiol. 56:331-338
Cretoiu, M. S., Korthals, G. W., Visser, J. H., and van Elsas, J. D. 2013. Chitin amendment increases soil suppressiveness toward plant pathogens and modulates the actinobacterial and oxalobacteraceal communities in an experimental agricultural field. Appl. Environ. Microbiol. 79: 5291-5301

de Weert, S., Vermeiren, H., Mulders, I. H., Kuiper, I., Hendrickx, N., Bloemberg, G. V., Vanderleyden, J., De Mot, R., and Lugtenberg, B. J. 2002. Flagella-driven chemotaxis towards exudate components is an important trait for tomato root colonization by Pseudomonas fluorescens. Mol. Plant-Microbe Interact. 15:1173-1180.

Dekkers, L. C., Bloemendaal, C. J. P., de Weger, L. A., Wijffelman, C. A., Spaink, H. P., and Lugtenberg, B. J. 1998. A two-component system plays an important role in the root-colonizing ability of Pseudomonas fluorescens strain WCS365. Mol. Plant-Microbe Interact. 11:45-56.

Else, M. A., and Jackson, M. B. 1988. Transport of 1-aminocyclopropane1-carboxylic acid (ACC) in the transpiration stream of tomato (Lycopersicon esculentum) in relation to foliar ethylene production and petiole epinasty. Aust. J. Plant Physiol. 25:453-458.

Espinosa-Urgel, M., Kolter, R., and Ramos, J. L. 2002. Root colonization by Pseudomonas putida: Love at first sight. Microbiology 148:341-343.

Etesami, H., Alikhani, H. A., and Hosseini, H. M. 2015. Indole-3-acetic acid and 1-aminocyclopropane-1-carboxylate deaminase: Bacterial traits required in rhizosphere, rhizoplane and/or endophytic competence by beneficial bacteria. Pages 183-258 in: Bacterial Metabolites in Sustainable Agroecosystem. D. K. Maheshwari, ed. Springer, Switzerland.

Frey-Klett, P., Burlinson, P., Deveau, A., Barret, M., Tarkka, M., and Sarniguet, A. 2011. Bacterial-fungal interactions: Hyphens between agricultural, clinical, environmental, and food microbiologists. Microbiol. Mol. Biol. Rev. 75:583-609.

Futamata, H., Sakai, M., Ozawa, H., Urashima, Y., Sueguchi, T., and Matsuguchi, T. 1998. Chemotactic response to amino acids of fluorescent pseudomonads isolated from spinach roots grown in soils with different salinity levels. Soil Sci. Plant Nutr. 44:1-7.

Gamalero, E., Berta, G., Massa, N., Glick, B. R., and Lingua, G. 2008. Synergistic interactions between the ACC deaminase-producing bacterium Pseudomonas putida UW4 and the AM fungus Gigaspora rosea positively affect cucumber plant growth. FEMS Microbiol. Ecol. 64 459-467.

Gaworzewska, E. T., and Carlile, M. J. 1982. Positive chemotaxis of Rhizobium leguminosarum and other bacteria towards root exudates from legumes and other plants. Microbiology 128:1179-1188.

Glick, B. R. 2012. Plant growth-promoting bacteria: Mechanisms and applications. Scientifica (Cairo) 2012:963401.

Glick, B. R. 2014. Bacteria with ACC deaminase can promote plant growth and help to feed the world. Microbiol. Res. 169:30-39.

Glick, B. R., Jacobson, C. B., Schwarze, M. M., and Pasternak, J. J. 1994. 1Aminocyclopropane-1-carboxylic acid deaminase mutants of the plant growth promoting rhizobacterium Pseudomonas putida GR12-2 do not stimulate canola root elongation. Can. J. Microbiol. 40:911-915.

Glick, B. R., Penrose, D. M., and Li, J. 1998. A model for the lowering of plant ethylene concentrations by plant growth-promoting bacteria J. Theor. Biol. 190:63-68.

Glick, B. R., Todorovic, B., Czarny, J., Cheng, Z., Duan, J., and McConkey, B. 2007. Promotion of plant growth by bacterial ACC deaminase. CRC Crit. Rev. Plant Sci. 26:227-242.

Gontia-Mishra, I., Sapre, S., Kachare, S., and Tiwari, S. 2017. Molecular diversity of 1-aminocyclopropane-1-carboxylate (ACC) deaminase producing PGPR from wheat (Triticum aestivum L.) rhizosphere. Plant Soil 414:213-227.

Gontia-Mishra, I., Sasidharan, S., and Tiwari, S. 2014. Recent developments in use of 1-aminocyclopropane-1-carboxylate (ACC) deaminase for conferring tolerance to biotic and abiotic stress. Biotechnol. Lett. 36: 889-898.

Greer-Phillips, S. E., Stephens, B. B., and Alexandre, G. 2004. An energy taxis transducer promotes root colonization by Azospirillum brasilense. J. Bacteriol. 186:6595-6604.

Grewal, S. I. S., and Rainey, P. B. 1991. Phenotypic variation of Pseudomonas putida and P. tolaasii affects the chemotactic response to Agaricus bisporus mycelial exudate. J. Gen. Microbiol. 137: 2761-2768.

Grichko, V. P., and Glick, B. R. 2001. Amelioration of flooding stress by ACC deaminase-containing plant growth-promoting bacteria. Plant Physiol. Biochem. 39:11-17.

He, K., and Bauer, C. E. 2014. Chemosensory signaling systems that control bacterial survival. Trends Microbiol. 22:389-398.

Heydarian, Z., Yu, M., Gruber, M., Glick, B. R., Zhou, R., and Hegedus, D. D. 2016. Inoculation of soil with plant growth promoting bacteria producing 1-aminocyclopropane-1-carboxylate deaminase or expression 
of the corresponding $a c d S$ gene in transgenic plants increases salinity tolerance in Camelina sativa. Front. Microbiol. 7:1966.

Hoang, T. T., Karkhoff-Schweizer, R. R., Kutchma, A. J., and Schweizer, H. P 1998. A broad-host-range Flp-FRT recombination system for site-specific excision of chromosomally-located DNA sequences: Application for isolation of unmarked Pseudomonas aeruginosa mutants. Gene 212:77-86.

Holguin, G., and Glick, B. R. 2001. Expression of the ACC Deaminase Gene fromEnterobacter cloacae UW4 in Azospirillum brasilense. Microb. Ecol. 41:281-288.

Hyodo, H., Hashimoto, C., Morozumi, S., Hu, W., and Tanaka, K. 1993. Characterization and induction of the activity of 1-aminocyclopropane1-carboxylate oxidase in the wounded mesocarp tissue of Cucurbita maxima. Plant Cell Physiol. 34:667-671.

Jackson, M. 1997. Hormones from roots as signals for the shoots of stressed plants. Trends Plant Sci. 2:22-28.

Jacobson, C. B., Pasternak, J. J., and Glick, B. R. 1994. Partial purification and characterization of 1-aminocyclopropane-1-carboxylate deaminase from the plant growth-promoting rhizobacterium Pseudomonas putida GR12-2. Can. J. Microbiol. 40:1019-1025.

Jayasinghearachchi, H. S., and Seneviratae, G. A. 2010. Mushroom-fungus helps improve endophytic colonization of tomato by Pseudomonas fluorescens through biofilm formation. Res. J. Microbiol. 5:689-695.

Jayasinghearachchi, H. S., and Seneviratne, G. 2004. Can mushrooms fix atmospheric nitrogen? J. Biosci. 29:293-296.

Kato, M., Hayakawa, Y., Hyodo, H., Ikoma, Y., and Yano, M. 2000. Wound-induced ethylene synthesis and expression and formation of 1aminocyclopropane-1-carboxylate (ACC) synthase, ACC oxidase, phenylalanine ammonia-lyase, and peroxidase in wounded mesocarp tissue of Cucurbita maxima. Plant Cell Physiol. 41:440-447.

Kende, H., and Zeevaart, J. 1997. The five "classical" plant hormones. Plant Cell 9:1197-1210.

Kim, H. E., Shitashiro, M., Kuroda, A., Takiguchi, N., and Kato, J. 2007. Ethylene chemotaxis in Pseudomonas aeruginosa and other Pseudomonas species. Microbes Environ. 22:186-189.

Kloepper, J. W., and Schroth, M. N. 1978. Plant growth-promoting rhizobacteria on radishes. Pages 879-882 in: Proceedings of the 4th International Conference on Plant Pathogenic Bacteria. Gilbert-Clarey, Tours, France.

Kong, Z., Glick, B. R., Duan, J., Ding, S., Tian, J., McConkey, B. J., and Wei, G. 2015. Effects of 1-aminocyclopropane-1-carboxylate (ACC) deaminase-overproducing sinorhizobium meliloti on plant growth and copper tolerance of Medicago lupulina. Plant Soil 391:383-398.

Kovach, M. E., Elzer, P. H., Hill, D. S., Robertson, G. T., Farris, M. A., Roop, R. M., 2nd, and Peterson, K. M. 1995. Four new derivatives of the broad-host-range cloning vector pBBR1MCS, carrying different antibiotic-resistance cassettes. Gene 166:175-176.

Li, J., Ovakim, D. H., Charles, T. C., and Glick, B. R. 2000. An ACC deaminase minus mutant of Enterobacter cloacae UW4 no longer promotes root elongation. Curr. Microbiol. 41:101-105.

Ling, N., Raza, W., Ma, J., Huang, Q., and Shen, Q. 2011. Identification and role of organic acids in watermelon root exudates for recruiting Paenibacillus polymyxa SQR-21 in the rhizosphere. Eur. J. Soil Biol. 47:374-379.

Liu, X., Wood, P. L., Parales, J. V., and Parales, R. E. 2009. Chemotaxis to pyrimidines and identification of a cytosine chemoreceptor in Pseudomonas putida. J. Bacteriol. 191:2909-2916.

Loake, G. J., Ashby, A. M., and Shaw, C. H. 1988. Attraction of Agrobacterium tumefaciens $\mathrm{C} 58 \mathrm{C} 1$ towards sugars involves a highly sensitive chemotaxis system. Microbiology 134:1427-1432.

Loyola-Vargas, V. M., Broeckling, C. D., Badri, D., and Vivanco, J. M. 2007. Effect of transporters on the secretion of phytochemicals by the roots of Arabidopsis thaliana. Planta 225:301-310.

Lugtenberg, B. J. J., Dekkers, L., and Bloemberg, G. V. 2001. Molecular determinants of rhizosphere colonization by Pseudomonas. Annu. Rev. Phytopathol. 39:461-490.

Lugtenberg, B. J. J., Kravchenko, L. V., and Simons, M. 1999. Tomato seed and root exudate sugars: Composition, utilization by Pseudomonas biocontrol strains and role in rhizosphere colonization. Environ. Microbiol. 1:439-446.

Ma, W., Sebestianova, S. B., Sebestian, J., Burd, G. I., Guinel, F. C., and Glick, B. R. 2003. Prevalence of 1-aminocyclopropane-1-carboxylate deaminase in Rhizobium spp. Antonie van Leeuwenhoek 83:285-291.

Masaphy, S., Levanon, D., Tchelet, R., and Henis, Y. 1987. Scanning electron microscope studies of interactions between Agaricus bisporus (Lang) Sing hyphae and bacteria in casing soil. Appl. Environ. Microbiol. 53:1132-1137.

Moe, L. A. 2013. Amino acids in the rhizosphere: From plants to microbes. Am. J. Bot. 100:1692-1705.
Moulton, R. C., and Montie, T. C. 1979. Chemotaxis by Pseudomonas aeruginosa. J. Bacteriol. 137:274-280.

Nascimento, F., Brígido, C., Alho, L., Glick, B. R., and Oliveira, S. 2012a Enhanced chickpea growth-promotion ability of a Mesorhizobium strain expressing an exogenous ACC deaminase gene. Plant Soil 353:221-230.

Nascimento, F. X., Brígido, C., Glick, B. R., Oliveira, S., and Alho, L. 2012b. Mesorhizobium ciceri LMS-1 expressing an exogenous 1aminocyclopropane-1-carboxylate (ACC) deaminase increases its nodulation abilities and chickpea plant resistance to soil constraints. Lett. Appl. Microbiol. 55:15-21.

Nascimento, F. X., Rossi, M. J., Soares, C. R., McConkey, B. J., and Glick, B. R. 2014. New insights into 1-aminocyclopropane-1-carboxylate (ACC) deaminase phylogeny, evolution and ecological significance. PLoS One 9:e99168.

Nascimento, F. X., Tavares, M. J., Glick, B. R., and Rossi, M. J. 2018 Improvement of Cupriavidus taiwanensis nodulation and plant growth promoting abilities by the expression of an exogenous ACC deaminase gene. Curr. Microbiol. 75:961-965.

Oku, S., Komatsu, A., Nakashimada, Y., Tajima, T., and Kato, J. 2014. Identification of Pseudomonas fluorescens chemotaxis sensory proteins for malate, succinate, and fumarate, and their involvement in root colonization. Microbes Environ. 29:413-419.

Oku, S., Komatsu, A., Tajima, T., Nakashimada, Y., and Kato, J. 2012. Identification of chemotaxis sensory proteins for amino acids in Pseudomonas fluorescens Pf0-1 and their involvement in chemotaxis to tomato root exudate and root colonization. Microbes Environ. 27:462-469.

Ordal, G. W., and Gibson, K. J. 1977. Chemotaxis toward amino acids by Bacillus subtilis. J. Bacteriol. 129:151-155.

Ouahrani-Bettache, S., Porte, F., Teyssier, J., Liautard, J. P., and Köhler, S. 1999. pBBR1-GFP: A broad-host-range vector for prokaryotic promoter studies. Biotechniques 26:620-622.

Pandey, J., Sharma, N. K., Khan, F., Ghosh, A., Oakeshott, J. G., Jain, R. K., and Pandey, G. 2012. Chemotaxis of Burkholderia sp. strain SJ98 towards chloronitroaromatic compounds that it can metabolise. BMC Microbiol. 12:19.

Penrose, D. M., and Glick, B. R. 2001. Levels of ACC and related compounds in exudate and extracts of canola seeds treated with ACC deaminase-containing plant growth-promoting bacteria. Can. J. Microbiol. 47:368-372

Penrose, D. M., and Glick, B. R. 2003. Methods for isolating and characterizing ACC deaminase-containing plant growth-promoting rhizobacteria. Physiol. Plant. 118:10-15.

Penrose, D. M., Moffatt, B. A., and Glick, B. R. 2001. Determination of 1aminocycopropane-1-carboxylic acid (ACC) to assess the effects of ACC deaminase-containing bacteria on roots of canola seedlings. Can. J. Microbiol. 47:77-80.

Pizarro-Tobías, P., Udaondo, Z., Roca, A., and Ramos, J. 2015. Events in root colonization by Pseudomonas putida. Pages 251-286 In: Pseudomonas. J. L. Ramos, J. Goldberg, and A. Filloux, eds. Springer, Dordrecht, The Netherlands.

Reinhold, B., Hurek, T., and Fendrik, I. 1985. Strain-specific chemotaxis of Azospirillum spp. J. Bacteriol. 162:190-195.

Rico-Jiménez, M., Muñoz-Martínez, F., García-Fontana, C., Fernandez, M., Morel, B., Ortega, A., Ramos, J. L., and Krell, T. 2013. Paralogous chemoreceptors mediate chemotaxis towards protein amino acids and the non-protein amino acid $\gamma$-aminobutyrate (GABA). Mol. Microbiol. 88:1230-1243.

Saharan, B. S., and Nehra, V. 2011. Plant growth promoting rhizobacteria: A critical review. Life Sci. Med. Res. 21:1-30.

Sarand, I., Österberg, S., Holmqvist, S., Holmfeldt, P., Skärfstad, E., Parales, R. E., and Shingler, V. 2008. Metabolism-dependent taxis towards (methyl)phenols is coupled through the most abundant of three polar localized Aer-like proteins of Pseudomonas putida. Environ. Microbiol. 10:1320-1334.

Seneviratne, G., and Jayasinghearachchi, H. S. 2003. Mycelial colonization by bradyrhizobia and azorhizobia. J. Biosci. 28:243-247.

Seneviratne, G., Weerasekara, M. L. M. A. W., Seneviratne, K. A. C. N., Zavahir, J. S., Kecskés, M. L., and Kennedy, I. R. 2010. Importance of biofilm formation in plant growth promoting rhizobacterial action. Pages 81-95 in: Plant Growth and Health Promoting Bacteria. D. K. Maheshwari, ed. Springer Berlin, Heidelberg.

Seneviratne, G., Zavahir, J. S., Bandara, W. M. M. S., and Weerasekara, M. L. M. A. W. 2008. Fungal-bacterial biofilms: Their development for novel biotechnological applications. World J. Microbiol. Biotechnol. 24: 739-743.

Shah, S., Li, J., Moffatt, B. A., and Glick, B. R. 1998. Isolation and characterization of ACC deaminase genes from two different plant growth-promoting rhizobacteria. Can. J. Microbiol. 44:833-843. 
Shennan, J. L. 2006. Utilisation of C2-C4 gaseous hydrocarbons and isoprene by microorganisms. J. Chem. Technol. Biotechnol. 81:237-256.

Simon, R., Priefer, U., and Pühler, A. 1983. A broad host range mobilization system for in vivo genetic engineering: Transposon mutagenesis in gram negative bacteria. Nat. Biotechnol. 1:784-791.

Smith, K. A., and Russell, R. S. 1969. Occurrence of ethylene, and its significance, in anaerobic soil. Nature 222:769-771.

Solano, B. R., Maicas, J. B., and Mañero, F. J. G. 2008. Physiological and molecular mechanisms of plant growth promoting rhizobacteria (PGPR). Pages 41-54 in: Plant-Bacteria Interactions: Strategies and Techniques to Promote Plant Growth. I. Ahmad, J. Pichtel, and S. Hayat, eds. Wiley, Weinheim.

Stromberger, M. E., Abduelafez, I., Byrne, P., Canela, M. M. (deceased), Elamari, A. A., Manter, D. K., and Weir, T. 2017. Genotype-specific enrichment of 1-aminocyclopropane-1-carboxylic acid deaminasepositive bacteria in winter wheat rhizospheres. Soil Sci. Soc. Am. J. 81:796-805.

Sun, Y., Cheng, Z., and Glick, B. R. 2009. The presence of a 1aminocyclopropane-1-carboxylate (ACC) deaminase deletion mutation alters the physiology of the endophytic plant growth-promoting bacterium Burkholderia phytofirmans PsJN. FEMS Microbiol. Lett. 296:131-136.

Suslow, T. V., and Schroth, M. N. 1981. Role of deleterious rhizobacteria as minor pathogens in reducing crop growth. Phytopathology 72:111-115.

Tan, S., Yang, C., Mei, X., Shen, S., Raza, W., Shen, Q., and Xu, Y. 2013. The effect of organic acids from tomato root exudates on rhizosphere colonization of Bacillus amyloliquefaciens T-5. Appl. Soil Ecol. 64: 15-22.

Timmusk, S., Paalme, V., Pavlicek, T., Bergquist, J., Vangala, A., Danilas, T., and Nevo, E. 2011. Bacterial distribution in the rhizosphere of wild barley under contrasting microclimates. PLoS One 6:e17968.

Tittabutr, P., Awaya, J. D., Li, Q. X., and Borthakur, D. 2008. The cloned 1aminocyclopropane-1-carboxylate (ACC) deaminase gene from Sinorhizobium sp. strain BL3 in Rhizobium sp. strain TAL1145 promotes nodulation and growth of Leucaena leucocephala. Syst. Appl. Microbiol. 31:141-150.
Vejan, P., Abdullah, R., Khadiran, T., Ismail, S., and Nasrulhaq Boyce, A. 2016. Role of plant growth promoting rhizobacteria in agricultural sustainability-a review. Molecules 21:573.

Velmourougane, K., Prasanna, R., and Saxena, A. K. 2017. Agriculturally important microbial biofilms: Present status and future prospects J. Basic Microbiol. 57:548-573.

Wallace, L. J., and Frazier, W. A. 1979. Photoaffinity labeling of cyclicAMP- and AMP-binding proteins differentiating Dictyostelium discoideum cells. Proc. Natl. Acad. Sci. U.S.A. 76:4250-4254.

Watanabe, K., Yamamoto, S., Hino, S., and Harayama, S. 1998. Population dynamics of phenol-degrading bacteria in activated sludge determined by gyrB-targeted quantitative PCR. Appl. Environ. Microbiol. 64: 1203-1209.

Yang, Y., M Pollard, A., Höfler, C., Poschet, G., Wirtz, M., Hell, R., and Sourjik, V. 2015. Relation between chemotaxis and consumption of amino acids in bacteria. Mol. Microbiol. 96:1272-1282.

Yuan, J., Zhang, N., Huang, Q., Raza, W., Li, R., Vivanco, J. M., and Shen, Q. 2015. Organic acids from root exudates of banana help root colonization of PGPR strain Bacillus amyloliquefaciens NJN-6. Sci. Rep. 5:13438.

Zhang, C., Huang, T., Shen, C., Wang, X., Qi, Y., Shen, J., Song, A., Qiu, L., and $\mathrm{Ai}, \mathrm{Y}$. 2016. Downregulation of ethylene production increases mycelial growth and primordia formation in the button culinarymedicinal mushroom, Agaricus bisporus (Agaricomycetes). Int. J. Med. Mushrooms 18:1131-1140.

Zheng, X. Y., and Sinclair, J. B. 1996. Chemotactic response of Bacillus megateriumstrain B153-2-2 to soybean root and seed exudates. Physiol. Mol. Plant Pathol. 48:21-35.

Zhulin, I. B. 2016. Classic spotlight: Genetics of Escherichia coli chemotaxis. J. Bacteriol. 198:3041.

\section{AUTHOR-RECOMMENDED INTERNET RESOURCE}

Joint Genome Institute genomic data: https://genome.jgi.doe.gov/programs/fungi/index.jsf 